\title{
Permeability Estimation of Fractured and Vuggy Carbonate Reservoir by Permeability Multiplier Method in Bai Hassan Oil Field Northern Iraq
}

\section{Sadeq QM*, Bhattacharya SK and Wan yusoff WIB*}

Department of Petroleum Geoscience, Universiti Teknologi Petronas, Malaysia

\begin{abstract}
A new method to diagnose and estimate secondary porosity and absolute permeability of fractured and vuggy carbonate formations based on the numerical simulation of the process of matrix solution technique developed and validated. The method includes the geological characterization of core laboratory data and their integration with well logs and rock production measurements. The new method to the interpretation of data acquired in a tertiary reservoir in Bai Hassan oil field applied. Cretaceous reservoir behaves as a triple-porosity petrophysical system which exhibits inter-crystalline, intra-crystalline, moldic, vuggy (connected and non-connected) and fractured porosity. Rockcore data and well tests indicate that vugs are the mayor component of secondary porosity while fractures and interconnected vugs account for most of the permeability. The initial phase of our interpretation method consists of integrating core measurements with well logs and well tests to calculate static and dynamic petrophysical properties via standard carbonate evaluation procedures. This procedure tested on several key wells with and without core measurements and well-testing measurements. Final estimates of porosity and permeability are in good agreement with the properties of the global petrophysical system been founded.
\end{abstract}

Keywords: Porosity; Permiability; Fracture; Petrophysical interpritation; Dry mineral; Archi formula; Matrix; Well log; Matrix solution technique

\section{Introduction}

Permeability estimation is one of the most important steps of reservoir characterization. Even though there are reliable methods to estimate porosity and fluid saturation, dependable permeability estimation is difficult, especially in carbonate reservoirs. In heterogeneous reservoirs with variable rock composition and petrophysical properties, integration of core measurements and well logs is necessary to predict petrophysical properties in zones with no or rare core samples. In this study, a single, unique poro-perm Transform is calculated for each stratigraphic formation to diagnose and estimate secondary porosity and absolute permeability of fractured and vuggy carbonate formations based on the numerical simulation of the process of matrix solution technique that takes place in complex reservoirs with a triple-porosity system (Figure 1). In so doing, we used well log, core and well tests to validate the estimation of petrophysical properties. Our

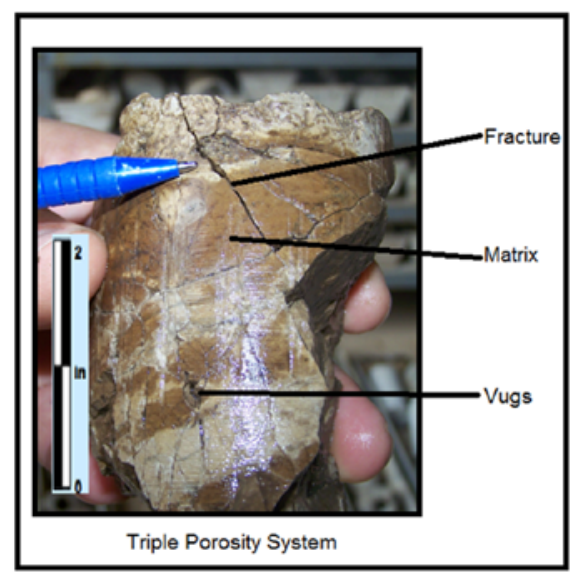

Figure 1: Typical distribution of porosity in the middle reservoir. The rock matrix is tight, exhibiting porosities from (2 to $10 \%$ ), whereas matrix permeability varies between $0.01 \mathrm{mD}$ and $100 \mathrm{mD}$. method includes the geological characterization of core measurements as well as integration of well logs and production data. We consider field data acquired in a reservoir located in the Kirkuk area north of Iraq, which is a prominent hydrocarbon producer in the Middle East. Facies in this reservoir consist of limestone, dolostone, dolostone, foraminiferal limestone and dolomitic limestone. Sedimentological studies describe these facies to represent deposition in a shallowmarine carbonate platform [1]. The volumetric concentration of each facies varies depending on the zone across the field. One of the most important observations is that the best oil-producing wells are located in zones with large amounts of dolomite, which in turn are associated with an increase of secondary porosity (interconnected vugs and fractures). Compared to previous characterization efforts in the same reservoir [1], our preliminary results show that the new method to estimate permeability is reliable in reservoirs with secondary porosity (vugs and fractures). Furthermore, the estimated permeability agrees well with permeability estimated from pressure transient tests (which is believed to be representative of the triple-porosity system). We performed the above estimation with the integration of all available information, thereby reducing uncertainty commonly associated with standard carbonate interpretation methods.

*Corresponding authors: Sadeq QM, Department of Petroleum Geoscience Universiti Teknologi Petronas, Malaysia, Tel: 9647701244627; E-mail: qase1967@yahoo.com

Wan yusoff WIB, Department of Petroleum Geoscience, Universiti Teknologi Petronas, Malaysia, Tel: +605 365 7079; E-mail: wanismail_wanyusoff@petronas.com

Received June 06, 2015; Accepted June 18, 2015; Published June 25, 2015

Citation: Sadeq QM, Bhattacharya SK, Wan Yusoff WIB (2015) Permeability Estimation of Fractured and Vuggy Carbonate Reservoir by Permeability Multiplier Method in Bai Hassan Oil Field Northern Iraq. J Pet Environ Biotechnol 6: 231. doi:10.4172/2157-7463.1000231

Copyright: () 2015 Sadeq QM, et al. This is an open-access article distributed under the terms of the Creative Commons Attribution License, which permits unrestricted use, distribution, and reproduction in any medium, provided the original author and source are credited. 
Citation: Sadeq QM, Bhattacharya SK, Wan Yusoff WIB (2015) Permeability Estimation of Fractured and Vuggy Carbonate Reservoir by Permeability Multiplier Method in Bai Hassan Oil Field Northern Iraq. J Pet Environ Biotechnol 6: 231. doi:10.4172/2157-7463.1000231

\section{General Description of the Bai Hassan Hydrocarbon Field}

The BAI HASSAN Field is one of the Iraq's giant oil fields with multiple pay zones similar to most of the northern Iraq oil fields (Figure 2). Bai Hassan field is one of several elongated, asymmetrical, doubly plunging anticlines that characterize the Foothills region of the Unstable Shelf Zone in eastern Iraq. The northwest-southeast trending structure measures $34 \mathrm{~km}$ long and $3.8 \mathrm{~km}$ wide. Bed dips on the flanks are approximately 40 degrees while the noses plunge at approximately 5 degrees. Two individual domes separated by a shallow saddle make up the Bai Hassan structure. Kithke Dome is the larger and more prolific of the two domes. It has a significant surface expression. Daoud Dome does not have a surface expression, is smaller, and less prolific. The Shahl Saddle physically separates the two domes. It is highly likely that the Shahl Saddle is associated with a deep seated, axis-perpendicular, extension fault that was reactivated and influential in the general structural development of Bai Hassan during Miocene compression and folding. The field's reserves are in three formations: (1) Oligocene Jeribe Formation with 36o API oil in a 130-m column; (2) Upper Qamchuqa (Mauddud) Formation with 29o API oil in a 125-m column; and (3) Upper part of Lower Qamchuqa (Shuaiba) Formation with $42^{\circ}$ API oil in a $175-\mathrm{m}$ column. So far, 184 wells have been drilled. The majority targeted the Oligocene reservoir, and more than half penetrated the Upper Qamchuqa (Mauddud) Formation. The field is an anticlinal structure located to the west of Kirkuk oil field which are all trends NWSE (Figures 1 and 2). It displays wide variations of rock composition and petrophysical properties and comprises a triple-porosity system (matrix, vugs and fractures), according to observations and analysis of rock- core measurements, well tests and well logs. The wide range of dolomite fabrics include microcrystalline, planar-e, planar-s, planar-p, non-planar as well as saddle and cement types. These fabrics imply successive phases of dolomitization, which profoundly influence the enhancement of reservoir character. Intercrystalline, micromoldic, and microvuggy porosity are the most influential by products of this dolomitization (Figure 3). Fracturing and stylolitization, in addition to the uniform network of intercrystalline pore systems, especially of the fine- to medium-crystalline dolomite, effectively contributed to the collective porosity and permeability of the reservoir.

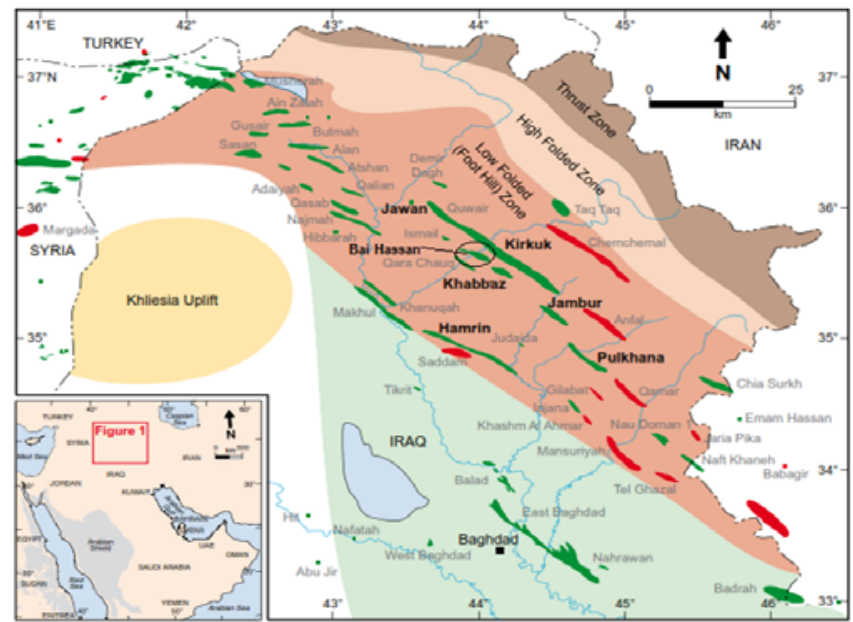

Figure 2: General location map showing oil fields and key wells in Iraq. BA HASSAN Field is located west of Kirkuk Field.

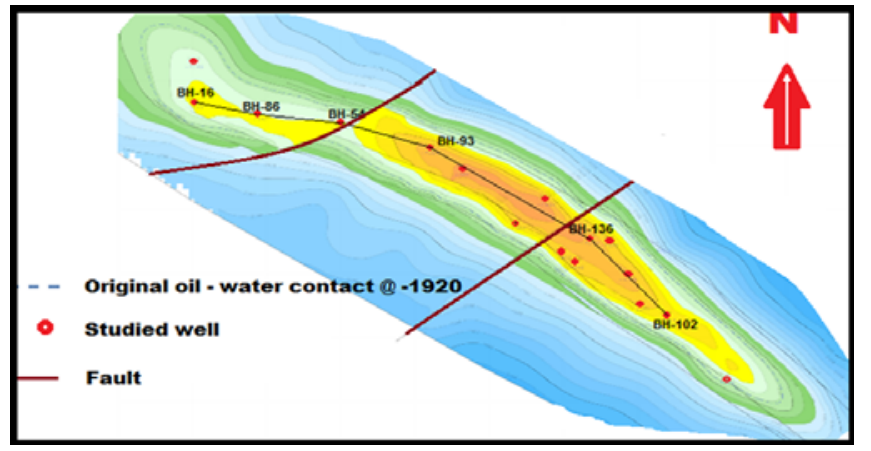

Figure 3: Structural contour map of BAI HASSAN Field on top of the Qamchuqa formation.

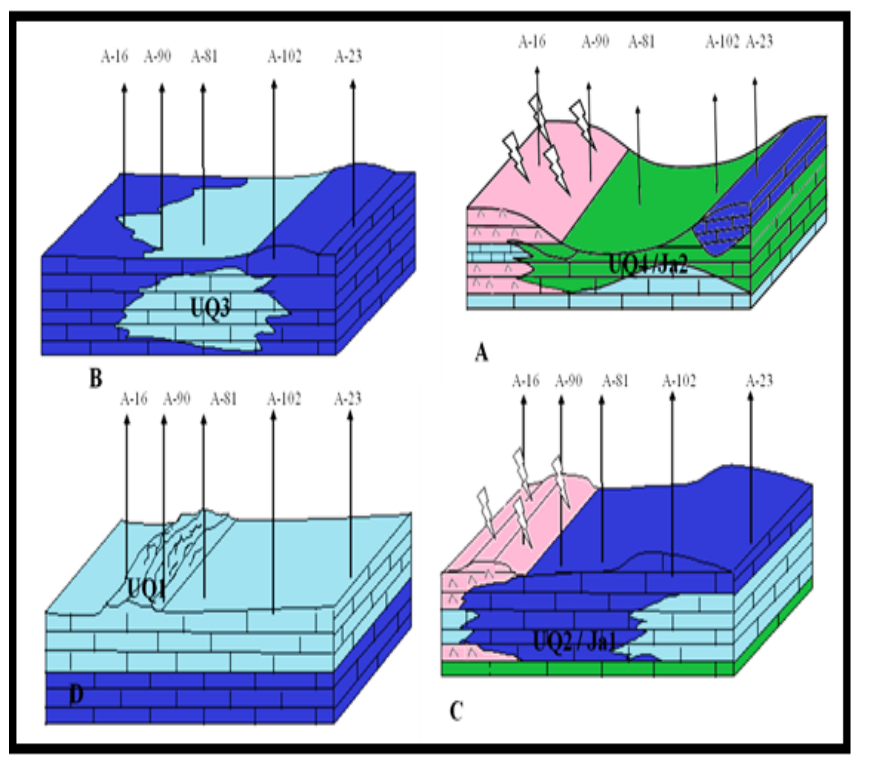

Figure 4: Depositional model for rock units: UQ1, UQ2, UQ3 and UQ4 of the upper Qamchuqa formation (excerpted from Qays, 2010, unpublished thesis).

\section{Sedimentary Model}

Facies in the middle reservoir are limestone, dolomitic limestone, dolostone, pelecypod limestone and foraminiferal limestone. Figure 4 shows results from sedimentological studies that describe these facies as representative of deposition in a shallow-marine carbonate platform. According to Ameen, during Cenomanian, the shallow marine reefal limestone of Qamchuqa formation was depositing in the studied area, which was making up northwestern margin of the Arabian platform. During Late Cenomanian, the studied area began to change from shallow marine facies (Qamchuqa formation) to deeper water facies (Kometan Formation). This depositional model was also confirmed by a recent study [1], which indicates that the carbonate sediments of the Qamchuqa formation predominantly consist of thinly- to thickly-bedded dolostones that were originally deposited as grain-rich to mud-rich limestone (e.g., skeletal grainstone and packstone, peloidal packstone and wackestone) on a shallow shelf. The volumetric concentration of each facies varies depending on location across the field. One of the most important observations is that the best oil-producing wells are located in zones with large amounts of dolomite that are also associated with an increase of secondary porosity 
Citation: Sadeq QM, Bhattacharya SK, Wan Yusoff WIB (2015) Permeability Estimation of Fractured and Vuggy Carbonate Reservoir by Permeability Multiplier Method in Bai Hassan Oil Field Northern Iraq. J Pet Environ Biotechnol 6: 231. doi:10.4172/2157-7463.1000231

(interconnected vugs and fractures). According to the stratigraphic column for the cretaceous middle reservoir, oil-producing formations belong to the Late Albian Mauddud formation [2].

\section{Method of Core-Log Integration}

Many interpretation methods are available to estimate permeability; most of them are based on empirical correlations between permeability, porosity, irreducible water saturation, pore throat radius, etc. According to Babadagli and Al-Sami [3] permeability estimation, methods can be grouped into two categories: pore-scale models and field-scale models. Most of the studies at the pore-level were performed on clastic rocks where the grain and pore properties were modeled quantitatively. The application of the latter models to carbonate rocks is moot because of their dependence on pore and grain properties. In general, it is difficult to accurately characterize complex carbonate reservoirs through grain and pore properties. Integration of core and log data is necessary to estimate permeability. The large variability observed in rock composition and petrophysical properties, coupled with a high degree of spatial heterogeneity, make it necessary to use indirect interpretation methods to estimate permeability.

In this work, we first implement a definition of rock types and establish a relationship with the geological model (structural and stratigraphic), facies, and spatial distribution of petrophysical properties. Second, a single, unique poro-perm transform is calculated for each stratigraphic formation. This method is made possible because of the large number of whole cores cut and thoroughly analyzed during Bai Hassan field delineation and development. The analysis performed in key wells is simplified by the abundance of information, such as core measurements, logs and pressure transient measurements. They enable the comparison of results against data acquired at different scales. Third, results obtained from the first approach are modified with petrophysical properties for the complete system (matrix, vugs, and fractures) observed in rock-core measurements and in well logs. This approach enables the estimation of secondary porosity (vugs and fractures) and the accurate estimation of permeability in the carbonate reservoir.

\section{Method Pressure transient analysis}

Pressure transient study followed the detailed methodology and goals discussed in the Tertiary section of this report. After extensive consistency and chart scanning quality checks, A was the sole cretaceous well found to have data to be of sufficient quality to conduct modern pressure transient analysis study. Interpretation renders the following observations for the upper qamchuqa completion test conducted in well A:

1. Early time pressure build-up response indicates possible fluid segregation effects on changing wellbore storage

2. Pressure derivative response in late time indicates presence of dual porosity system with interpreted values for storativity ratio and interporosity flow coefficient of 0.371 and $5.85 \mathrm{e}-6$ respectively.

3. System flow capacity is estimated at $11,000 \mathrm{md}-\mathrm{ft}$ using data from the a final well report.

Similar to Tertiary findings, this aspect of study proved challenging in obtaining meaningful insight to the extent of acquiring reservoir fracture characteristics. Unfortunately, the aspiration to acquire critical fracture parameters through PTA for use in conditioning 3D reservoir flow models did not yield results of statistical significance. In absence of both detailed core reports and advanced formation imaging data, empirical methods such as detailed rock outcrop study will be required to understand local fracture systems. The use of modern high-resolution electronic gauges in all future pressure buildup and drawdown well tests will enable use of modern pressure derivative analysis techniques. The $\mathrm{dp} \& \mathrm{dp}$ ' versus dt diagnostic interpretation plot for A well data is depicted in Figure 5.

\section{Permeability Multiplier}

Fracture density by itself is not a useful attribute in this study except to qualitatively highlight areas where production might be enhanced due to increased fracturing. The fracture density value, therefore, is converted to a permeability multiplier using a logarithmic transformation (Figure 6). The permeability multiplier value, by definition, cannot be less than one. A multiplier less than one would cause a reduction in total permeability, which violates the lithologymodified permeabilities, and effectively reduces the contribution of fractures to permeability already predicted by the structural model. A logarithmic function provides the formula for converting fracture density values to permeability multipliers. Fracture density is converted to a permeability multiplier by a logarithmic formula. The permeability multiplier must be greater than one (1) in order to retain all the permeability influences of structure, lithology, and bed thickness. If 'a' is small then the contribution due to fractures is also small resulting in a multiplier close to one. This would suggest that the matrix permeability

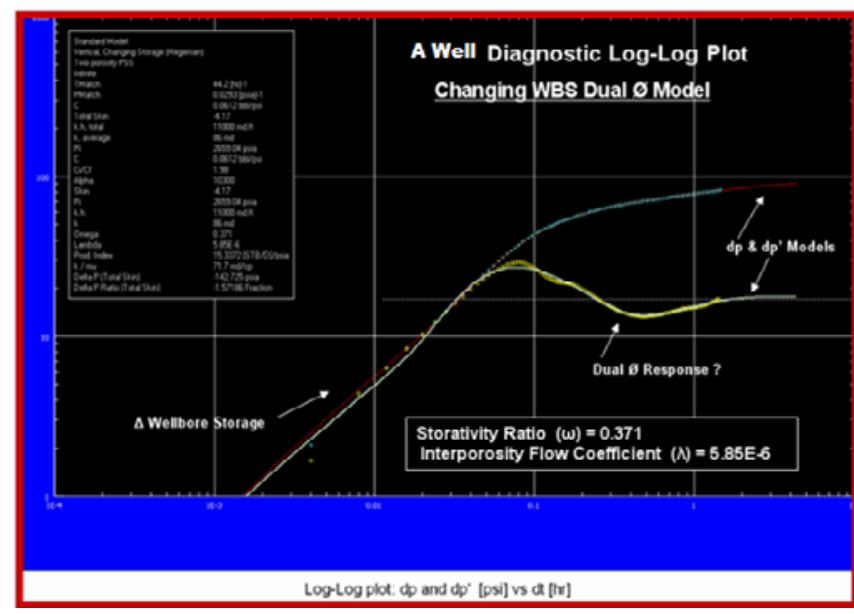

Figure 5: A well UQ pressure transient analysis-dual $\varnothing$ model.

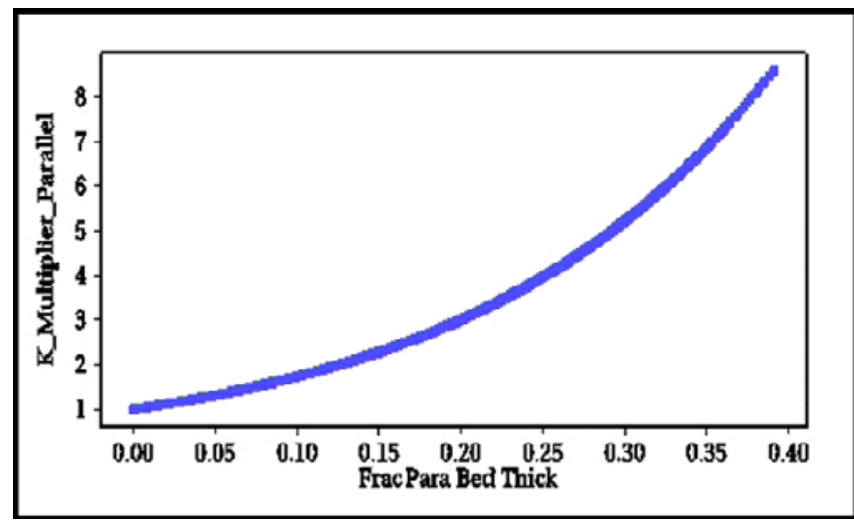

Figure 6: Conversion of fracture density to perm multiplier. 


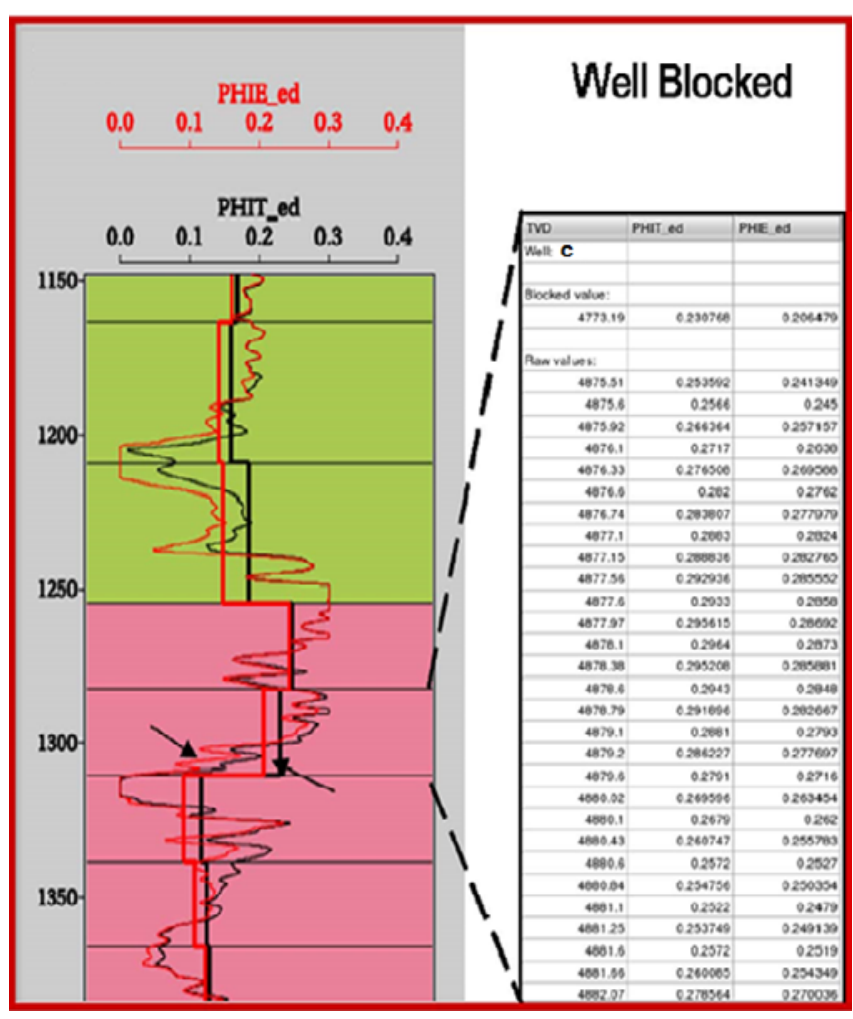

Figure 7: Comparison of PHIE and PHIT in blocked wells.

adequately describes the fluid flow and matches the well history.

Fracture density (D) and permeability, ultiplier

$\mathrm{K}^{*}=10^{\mathrm{D}^{*} \mathrm{a}}$

"a" is a scaler to adjust the influence of D to K

- If if $\mathrm{a}=1$ and $\mathrm{D}=0 \approx 0.4 \mathrm{~m} / \mathrm{m}^{2}$

- Scaler a can be found by deciding what max

$\mathrm{K}^{\star}$ to be 10 and its relationship to $\mathrm{D}$ max.

- i.e. $\mathrm{a}=\log ^{\star} \max / \mathrm{D} \max$.

- For example, if we want the $\max K^{*}$ to be 10 , then $\mathrm{a}=\log 10 / 0.3=3.33$.

Therefore, $\mathrm{K}^{*}=10 \mathrm{D}^{\star 3} 3.3310^{\mathrm{D}^{* 3.33}}$

Fracture Density is converted to a permeability multiplier by a logarithmic formula. The PermMultiplier must be greater than one (1) in order to retain all the permeability influences of structure, lithology, and bed thickness. If ' $a$ ' is small then the contribution due to fractures is also small resulting in a multiplier close to one. This would suggest that the matrix permeability adequately describes the fluid flow and matches the well history. Finally, the Permeability Multiplier multiplies matrix permeability determined from core plugs, thereby, changing the PERMX and PERMY flow properties (anisotropy) across the Bai Hassan structure to allow a better match of well production histories. This can be done by applying a different set of multipliers to each of the unique fracture sets independently of each other to preferentially vary fluid flow in one direction over another direction. The fracture density enhances the matrix permeability proportionally.
This example from layer 8 (top Baba Fm.) illustrates the effect of the Perm Multiplier. Inside the red circle, matrix permeability values range from approximately 1-106 md. After applying the multiplier (2-62-fold increase), total permeability values range from 2 - over $3000 \mathrm{md}$. The increase is attributed to the predicted presence of a significant axisperpendicular fracture set.

Finally, the Permeability Multiplier multiplies matrix permeability determined from core plugs, thereby, changing the PERMX and PERMY flow properties (anisotropy) across the Bai Hassan structure to allow a better match of well production histories. This can be done by applying a different set of multipliers to each of the unique fracture sets independently of each other to preferentially vary fluid flow in one direction over another direction. The fracture density enhances the matrix permeability proportionally. This example from layer 8 (top Baba Fm.) illustrates the effect of the Perm Multiplier. Inside the red circle, matrix permeability values range from approximately 1-106 md.

After applying the multiplier (2-62 fold increase), total permeability values range from $2-3000 \mathrm{md}$. The increase is attributed to the predicted presence of a significant axis-perpendicular fracture set.

\section{Porosity}

There are two types of porosity logs displayed in the model data queue; namely, PHIT (total porosity) and PHIE (effective porosity). Total porosity, PHIT, is determined directly from wireline log observations (sonic, density, neutron). Effective porosity, PHIE, is created using reservoir flag logs as the bias logs. The effective porosity log preserves the porosity values from reservoir quality rock, like dolomite and limestone, by filtering out porosity values from nonreservoir rock, like shale (clay), anhydrite and salt. This becomes important when blocking wells that may have high porosity streaks due to shales or some other non-reservoir rock type. The Tertiary section at BAI HASSAN is almost exclusively reservoir quality carbonate; therefore, PHIT and PHIE are essentially equal. The Cretaceous section, however, has a greater amount of non-reservoir quality rock mixed in the section; therefore, PHIT is optimistically high compared to PHIE. Effective porosity, PHIE, has the high porosity, non-reservoir shale values removed from well blocking and is the preferred porosity value distributed in the BAI HASSAN models. Figure 7 shows PHIT and PHIE comparisons for one cretaceous well.

\section{Lithology}

Four reservoir rock types are calculated during the petrophysical analysis from electric log data, namely, shale (VSH), limestone (VLMST), dolomite (VDOLO), and anhydrite (VANHY). The petrophysical workflow and calculations are described in greater detail in the petrophysical section of this report. The lithology logs (Figure 8) created from these curves is loaded as raw curves into RMS. Well blocking and petrophysical modeling similar to the procedures used to upscale and distribute the porosity curves is applied to each of the newly created lithology curves. These lithology parameters play a key role in creating the fracture model by modifying the fracture density applied to the reservoirs. Dolomite is brittle and, therefore, enhances fracture development, whereas, layers with high volumes of ductile shale or anhydrite reduce the fracture density. Interpreted lithology log for well B (on left) showing the volumes of the rock types calculated from the petrophysical evaluation. The log on the right shows the upscaled VDOLO block log and the original VDOLO curve from the Baba section. The blocked log values are used in modeling the distribution of lithology across the structure [4]. 
Citation: Sadeq QM, Bhattacharya SK, Wan Yusoff WIB (2015) Permeability Estimation of Fractured and Vuggy Carbonate Reservoir by Permeability Multiplier Method in Bai Hassan Oil Field Northern Iraq. J Pet Environ Biotechnol 6: 231. doi:10.4172/2157-7463.1000231

Page 5 of 7

This example shows the effect of higher porosity non-reservoir rock on PHIE and PHIT. PHIE (red) is the curve that best represents the reservoir and is used in the study. The table on the right lists a portion of the individual log readings that are averaged to calculate the blocked well value for.

Interpreted lithology log for well B (on left) showing the volumes of the rock types calculated from the petrophysical evaluation. The log on the right shows the upscaled VDOLO block log and the original VDOLO curve from the Baba section. The blocked log values are used in modeling the distribution of lithology across the structure.

\section{Permeability}

Permeability is not directly measured in wells and, as such, requires an indirect method for populating the field. Permeability, consequently, is calculated from porosity data using simple equations derived from porosity-permeability measurements made on well core plugs. A single, unique poro-perm transform is calculated for each stratigraphic

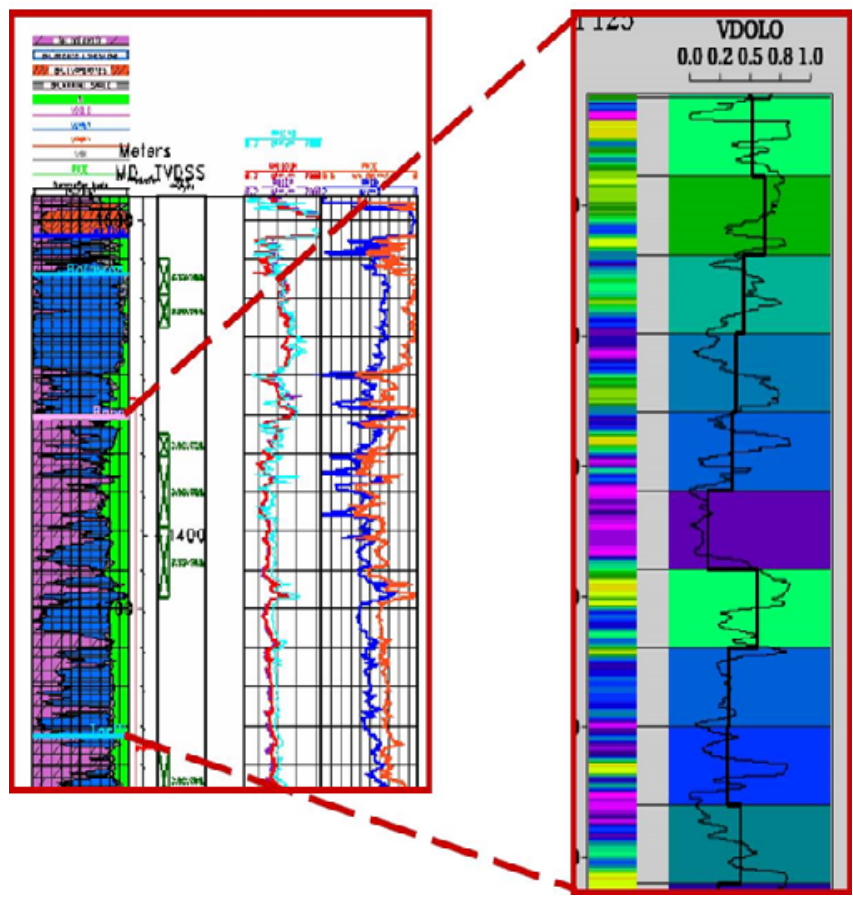

Figure 8: Interpreted lithology Log B. formation. This method is made possible because of the large number of whole cores cut and thoroughly analyzed during Bai Hassan field delineation and development. While it is routine that cores are cut in major reservoirs, another extra steps to core virtually every horizon at several locations around the field, thereby, capturing a representative look at the variability of each formation. It is highly recommended that a more comprehensive analysis of the core data be undertaken in order to develop multiple transforms for each horizon. Core plug porosity and permeability data was sorted and graphed by formation.

A "best-fit" line was calculated that relates a measured porosity value to a measured permeability value. Each rock unit with a porosity value is then populated with a permeability value calculated from the porosity-permeability transform equation unique to its formation. The transformations are performed at the layer level to preserve the relationship between the effective porosity (PHIE) trends and the influence of lithology. Table 1 is a comparison of the core measured values and the values from the transform equation.

\section{Results}

\section{Shiranish}

All whole core plug permeability values were measured as $0.01 \mathrm{md}$. This is suspicious and may be an indication of either: Rock that is so tight that the values are too small to accurately measure or Problems in the testing procedure. Since the permeability measurements for all porosities were $0.01 \mathrm{md}$, the Transform equation probably does not accurately reflect the range of Permeabilities.

\section{Mushorah/Kometan}

The permeability values calculated from the poro-perm transform and, subsequently distributed in a range from $0.01 \mathrm{md}$ to $2.8 \mathrm{md}$. The plot shows that some low porosity-hi permeability rocks are present (red oval) and not adequately captured in the simple transform. The inability of the transform to capture this trend may be explained by the presence of more than one facies in the rock samples (Figure 9).

\section{Upper Qamchuqa (Mauddud)}

The data table shows that the range of permeability values between the core data and the Transform equation data are in fairly good agreement. The core data ranges from $0.01 \mathrm{md}$ to $481 \mathrm{md}$ while the data distributed in the model ranges from $0.01 \mathrm{md}$ to almost $300 \mathrm{md}$ using the transform function. The wide range of values at any single porosity value or permeability value, however, suggests more than one petrophysical facies is contained in the data set. Average Permeabilities

\begin{tabular}{|c|c|c|c|c|c|c|c|c|}
\hline \multirow[t]{2}{*}{ Formation } & \multicolumn{4}{|c|}{ Core } & \multicolumn{4}{|c|}{ Transform equation } \\
\hline & $\begin{array}{c}\text { Porosity Range } \\
\text { (fract) }\end{array}$ & $\begin{array}{l}\text { Porosity Avg. } \\
\text { (fract) }\end{array}$ & Perm Range (md) & Perm Avg. (md) & $\begin{array}{l}\text { Porosity Range } \\
\text { (fract) }\end{array}$ & $\begin{array}{l}\text { Porosity Avg. } \\
\text { (fract) }\end{array}$ & Perm Range (md) & Perm Avg. (md) \\
\hline Jerlbe & $0.01-0.30$ & 00.08 & $0.01-377$ & 6.4 & $0.01-0.23$ & 00.08 & $0.01-82$ & 1.2 \\
\hline Bajawan & $0.01-0.40$ & 00.09 & $0.01-2025$ & 44.2 & $0.01-0.37$ & 00.08 & $0.14-1591$ & 8.9 \\
\hline Baba & $0.01-0.46$ & 0.19 & $0.01-6981$ & 105 & $0.01-0.33$ & 0.16 & $0.02-2987$ & 9.7 \\
\hline Tarjil & $0.01-0.25$ & 0.14 & $0.01-231$ & 1.7 & $0.06-0.27$ & 0.15 & $0.05-9.8$ & 0.6 \\
\hline Shiranish & $0.01-0.10$ & 00.04 & no data & no data & $0.01-0.15$ & 00.06 & 00.01 & 00.01 \\
\hline Mush/Kom & $0.01-0.29$ & 0.1 & $0.01-62$ & 1.2 & $0.01-0.22$ & 00.04 & $0.01-2.7$ & 00.06 \\
\hline U.Qamchuqa & $0.01-0.36$ & 0.11 & $0.01-284$ & 16.1 & $0.02-0.31$ & 0.13 & $0.02-482$ & 6.3 \\
\hline Jawan & $0.01-0.17$ & 00.02 & $0.01-16$ & 0.2 & $0.01-0.13$ & 00.04 & $0.01-70.0$ & 0.3 \\
\hline L.Qamchuqa & $0.01-0.21$ & 00.07 & $0.01-86$ & 1.6 & $0.01-0.14$ & 00.03 & $0.01-2.1$ & 0.1 \\
\hline
\end{tabular}

Table 1: Comparison of measured and transform equation perms. 
Citation: Sadeq QM, Bhattacharya SK, Wan Yusoff WIB (2015) Permeability Estimation of Fractured and Vuggy Carbonate Reservoir by Permeability Multiplier Method in Bai Hassan Oil Field Northern Iraq. J Pet Environ Biotechnol 6: 231. doi:10.4172/2157-7463.1000231

Page 6 of 7

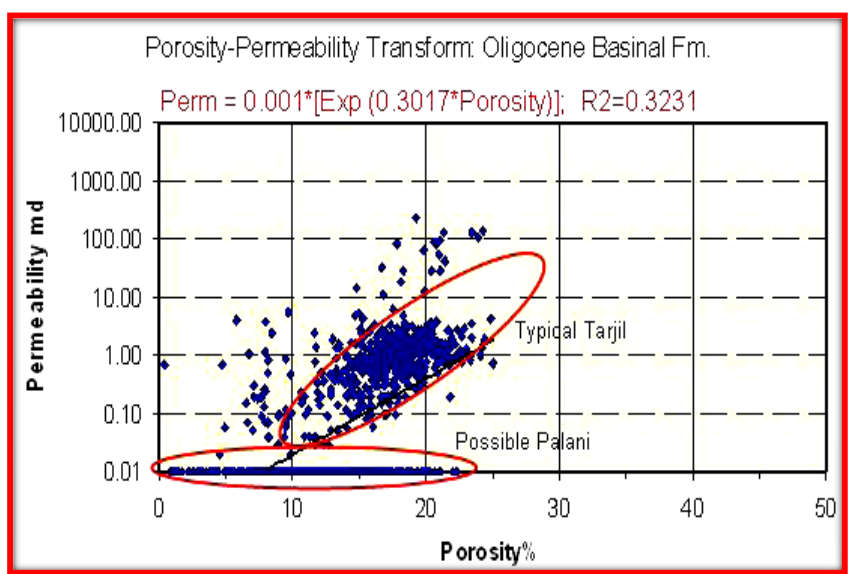

Figure 9: Poro-perm transform-oligocenebasinal formation.

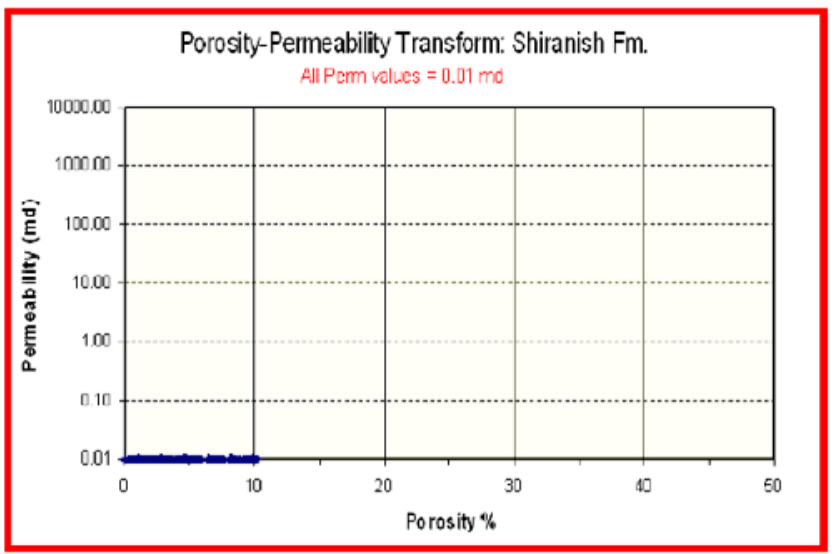

Figure 10: Poro-perm transform-Shiranish formation

are $16.1 \mathrm{md}$ and $6.3 \mathrm{md}$ from core plug measurements and the Transform equation, respectively (Figure 10).

\section{Jawan}

The facies change in the Jawan formation creates a need for two different transform functions in order to allow for lithologic differences. Application of the transform, consequently, was dependent on the lithology. Any rock unit that contained anhydrite used the "low perm" transform. Similarly, the "high perm" transform was applied to rock units without anhydrite, which typically occurred on Kithke dome (Figures 11 and 12).

\section{Qamchuqa (Shuaiba)}

Most of the wells drilled into the Cretaceous penetrated the top of the L. Qamchuqa; however, only four wells have been completed in the interval. Abundant core data is available, albeit from the top of the unit, to calculate a representative porosity-permeability transform. The scatter around the poro-perm trend line, once again, illustrates the existence of multiple petrophysical facies. The simple transform created from the core data, consequently, does not effectively capture the high-end Permeabilities in the Transform equation. Permeabilities measured in the core range from $0.01 \mathrm{md}$ to $86 \mathrm{md}$ (Figure 13).

\section{Discussion}

Lucia's [5] interpretation method proposes the estimation of porosity and permeability of non-vuggy carbonate reservoirs with relationships between porosity and permeability for specific particlesize groups. We implemented this approach to our data. In addition, we implemented a definition of rock types based on both rock fabric

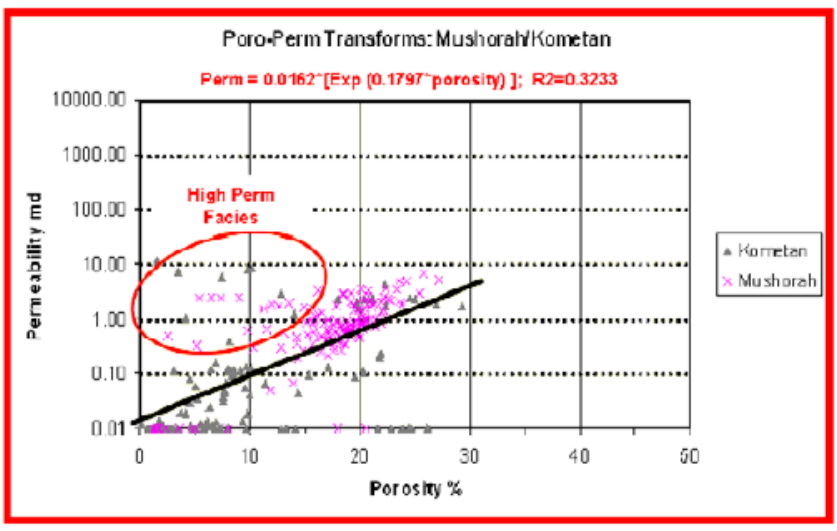

Figure 11: Poro-perm transform-Mushorah formation.

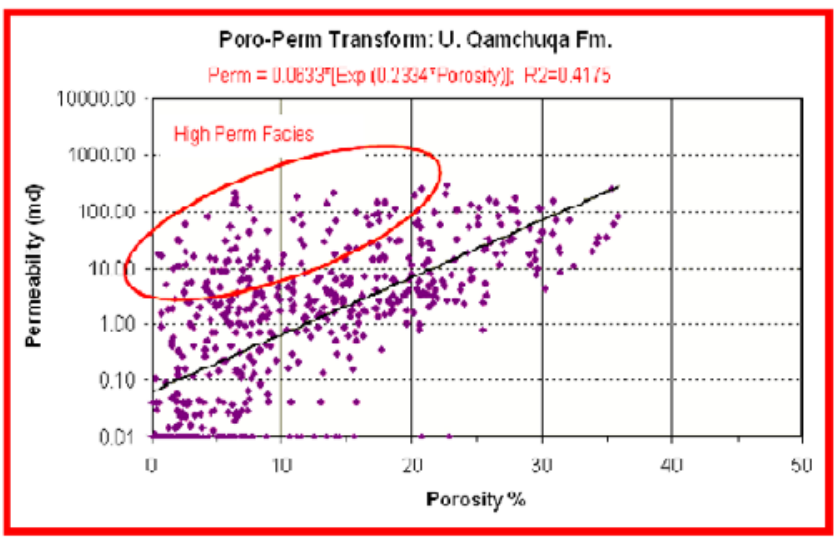

Figure 12: Poro-perm transform-U. Qamchuqaformation.

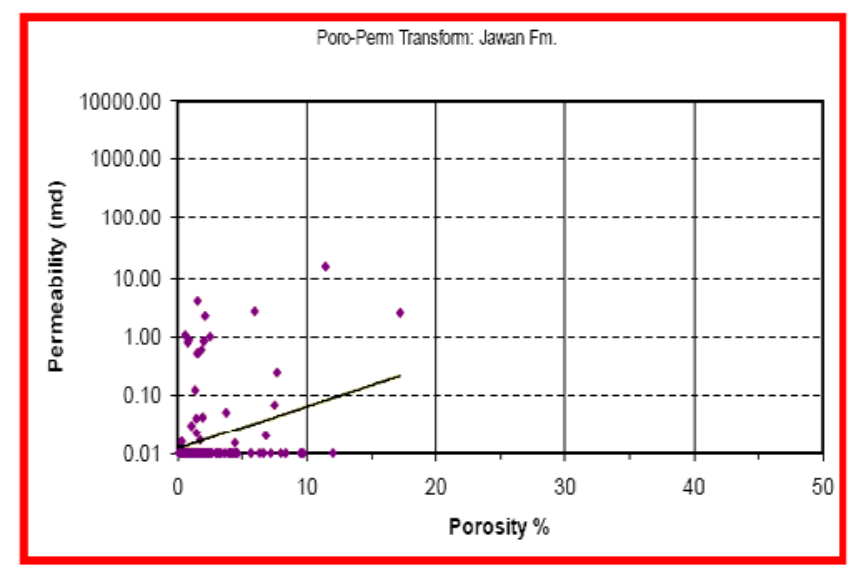

Figure 13: Poro-perm transform-Jawanformation. 


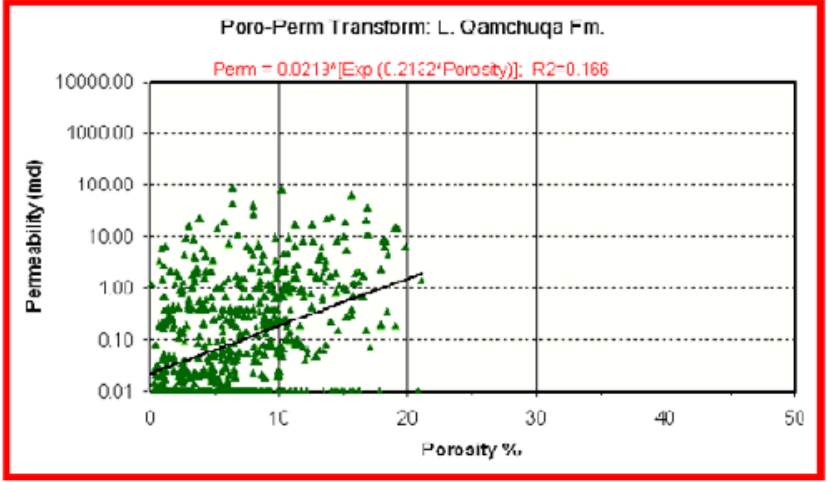

Figure 14: Poro-perm transform-L. Qamchuqaformation.

and critical pore-throat radius using rock-core measurements (Figure 14).

We believe that a combination of the previous two approaches permits a better petrophysical characterization of the matrix. However, the two methods did not allow us to quantify porosity and permeability of vugs and fractures. Vugs and fractures in the upper Qamchuqa reservoir could cause significant differences between the petrophysical properties obtained with the two approaches. Presence of connected vugs and fractures will be estimated in those Based on the above observations, we developed and validated an interpretation method to estimate permeability of the entire petrophysical system (matrix, vugs, and fractures). Results from our study favor the the porosity-permeability transform equation unique to its formation to estimate the permeability of the composite petrophysical system. Despite difficulties and limitations associated with the uncertainty of some simulation parameters [6]. The following is an itemized list of sequential steps for the application of the proposed interpretation method based on the porosity-permeability transform equation unique to its formation modeling:

- Define rock types from both rock fabric and critical pore-throat radius using rock-core measurements.

- Identify presence of secondary permeability and porosity due to presence of fractures, interconnected vugs, intercrystalline and intercrystalline porosity, or the combination of any of these components.

- Estimate initial rock-properties (porosity, permeability and water saturation) from well-log correlations and via integrated petrophysical assessment.

- Calculate and/or measure capillary pressure and relative permeability from rock-core measurements and describe these properties with Brooks-Corey's equations and parameters.

- Progressively make perturbations to the permeability of each layer until securing a match between simulated and measured apparent resistivity curves.

- Compare the results obtained with permeability estimated from pressure transient measurements and observations of fractures and vugs from core analysis.

\section{Conclusions}

In this study developed and successfully tested a new unique method to diagnose and quantify fractured and vuggy carbonate formations via the simulation of the process of the porosity-permeability transform equation. The method was applied to a several wells drilled in the carbonate reservoirs in BAI HASSAN oil field northern Iraq. Pressure transient measurements combined with core measurements enabled the diagnosis of vugs and fractures that significantly contributed to the total porosity and permeability of the composite petrophysical system. By Matching and simulating the process of the porosity-permeability, transform equation to these perturbations were used to diagnose presence of secondary porosity and permeability. We introduced a simple graphical procedure to diagnose the individual relative influence of either vugs or fractures on the porosity and permeability of the composite petrophysical system. Permeability estimated from the case studies was consistent with permeability estimated from pressure transient measurements (which experience shows are representative of the composite petrophysical system) [7]. Even though additional testing is necessary to generalize the applicability and reliability of our interpretation method, the availability of a cross-validation procedure to verify petrophysical estimates is by itself an important advantage of the proposed interpretation method. The interpretation method introduced in this paper requires reliable non-conventional petrophysical information for its implementation, including relative permeability and capillary pressure. Assumption estimated values of porosity and permeability should be regarded as effective medium approximations of the composite petrophysical system.

\section{References}

1. Sadeq QM (2010) Facies analysis and Reservoir modelling, Bai Hassan oil field north of Iraq. Unpublished MSc thesis, Universiti Teknologi Petronas, Malaysia, p. 119.

2. Aguilera R (1995) Naturally Fractured Reservoirs (2ndedn). Penwell Books.

3. Babadagli T, Al-Salmi S (2004) A Review of Permeability-Prediction Methods for Carbonate Reservoirs Using Well-Log Data, SPE Reservoir Evaluation and Engineering.

4. Corey AT (1994) Mechanics of Immiscible Fluids in Porous Media. Water Resource Publications.

5. Lucia FJ (2007) Carbonate Reservoir Characterization-An Integrated Approach (2ndedn). Springer.

6. Werdi AN (2001) Sequence stratigraphy of the Lower Cretaceous formations in Bai Hassan, Khabbaz and Jambour oil fields, Northeastern Iraq. Unpublished PhD thesis, University of Baghdad, Iraq, p. 143.

7. Lucia FJ (2004) Origin and petrophysics of dolostone pore space. In Braithwaite CJ, Rizzi G, Darke G (rds.) The geometry and petrogenesis of dolomite hydrocarbon reservoir. Geological Society of London Special, pp. 141-155. 